Anuario Latinoamericano Ciencias Políticas

y Relaciones Internacionales

vol. 8, 2019

pp. 279-294

\section{Entre lo dicho y lo hecho cuando se trata de mujeres}

\section{Between What Is Said and What Is Done When It Comes to Women's Issues}

\author{
Mariano Eugenio Antón * \\ UNIVERSIDAD NACIONAL DE MISIONES \\ POSADAS, ARGENTINA \\ $\triangle$ mariano.anton@campus.unam.edu.ar \\ https://orcid.org/0000-0002-1288-7994
}

\title{
RESUMEN
}

En el presente trabajo se buscó indagar respecto a la institucionalización o no de los espacios concebidos por la ley como necesarios a los fines del desarrollo de políticas públicas vinculados a violencia hacia la mujer. Se detectó que dichos ámbitos pensados legalmente no siempre encuentran su correlato en el diseño institucional de manera efectiva, $y$, por ende, entendemos que de ello existe la posibilidad de atribuir responsabilidades concretas ante la omisión o deficiente prestación del servicio requerido al Estado.

PALABRAS CLAVE: violencia, mujer, responsabilidad estatal.

\begin{abstract}
In this paper, we sought to investigate the institutionalization or not of spaces conceived by law as necessary for the development of public policies linked to violence against women. It was detected that these legally thought areas do not always find their correlate in the institutional design in an effective manner, therefore, we understand that there is the possibility of assigning specific responsibilities in view of the omission or deficient provision of the service required by the State.
\end{abstract}

KEYWORDS: violence, woman, state responsibility.

* Abogado, Magister en Gestión Pública. Docente de grado y posgrado de la Universidad Nacional de Misiones y Universidad Gaston Dachary. 
Dossier

América Latina: género y política

\section{Introducción}

Hemos decidido indagar sobre la institucionalidad generada a partir de lo que la norma jurídica ha considerado como necesario o adecuado para abordar la problemática de violencia hacia las mujeres en la Provincia de Misiones, Argentina.

De un tiempo a la fecha los Estados han comenzado a diseñar propuestas normativas para contribuir a disminuir la violencia hacia la mujer. Pero también es posible observar que en muchos casos esos avances normativos han sido solo normativos, dado que no siempre han logrado ser plasmados en políticas públicas concretas e inclusive no se han materializado los espacios institucionales pertinentes al compromiso asumido.

Diversos son los estudios que analizan el fenómeno de la violencia contra las mujeres, pero poco se ha dicho sobre las respuestas institucionales que en definitiva pueden favorecer o entorpecer los mecanismos pensados normativamente para tutelar a la mujer víctima de violencia.

La magnitud del fenómeno de la violencia hacia la mujer en Argentina es grave y nos hace notar investigaciones como las de la Organización Civil la Casa del Encuentro, que por medio de su Observatorio de Femicidios en Argentina se afirma que es posible estimar que cada 30 horas, en el país, una mujer es asesinada a manos de un familiar, pareja o expareja. Ello da cuenta de la existencia de un complejo -e ineludible- problema social, cuya naturaleza misma -en tanto que atropello a los derechos humanos- compete sobremanera al Estado. Del mismo informe se destaca la provincia de Misiones dado su alto número de femicidios anuales.

En Argentina, poco se ha avanzado en la indagación sobre cómo o con qué herramientas los y las agentes estatales afrontan diariamente el desafío de encontrar respuestas que contribuyan a que una mujer pueda comenzar a salir de una vida de violencia, por lo que recibe cuestionamientos en el ámbito internacional por la falta de investigaciones e información generada desde el Estado $\mathrm{y}$ con un alcance que pueda calificarse de federal.

Este trabajo lo hemos realizado conscientes de que cuando una mujer atraviesa el dolor y temor de una vida violentada, cuando se sabe en riesgo de vida y, por ende, acude a hacer pública su situación presentándose en alguna dependencia estatal, es porque seguramente ya ha agotado otras instancias, y es por ello que allí la respuesta institucional no puede ni debe ser deficitaria.

Ello porque en los casos de violencia sistémica hacia una mujer, generalmente le resultará muy difícil reconocerse como víctima, y de lograrlo, se atreva a intentar revertir dicha situación buscando ayuda. Ahora bien, aquellas que logran dar los pasos iníciales para salir de una vida violenta y deciden buscar ayuda, comienzan a transitar lo que comúnmente se denomina la "ruta crítica",

1 El concepto "Ruta Crítica" surge en los trabajos de investigación desarrollados por la Organización Panamericana de la Salud (OPS) al indagar sobre la situación de las mujeres sometidas a violencia intrafamiliar. 
y en esa ruta, de ser el caso que la mujer se encontrase con instituciones carentes de respuestas, de recursos, de profesionales preparados, llena de silencios por parte de quienes le tienen que brindar respuestas institucionales, seguramente la situación generará en ella arrepentimiento y aumento de la sensación de vulnerabilidad, cuyo resultado será el posible fracaso del sistema que la normatividad vigente ha querido garantizar.

Vale tener en cuenta que, para la víctima, acudir al sistema tutelar legal resulta ser una experiencia dura, traumática y costosa emocionalmente (Ulloa González, 2009, p. 278) y, por ende, no es dable aceptar que el sistema de contención se debilite por inoperancias o prejuicios de las más diversas índoles.

Partimos de la idea de que, si el Estado ha creído necesario crear una norma, que a su vez propone el desarrollo de un espacio institucional, al que indefectiblemente le deberá asignar recursos para materializar sus objetivos, es porque ha identificado una necesidad o problema a ser abordado.

Y si esa respuesta resulta ser inexistente o deficiente, hay alguien que indudablemente no está cumpliendo con su responsabilidad.

\section{Entre el debe ser y el es}

Para analizar la legislación vigente hemos acudido al Digesto Jurídico Provincial que nos permitió una búsqueda certera sobre las leyes que se encuentran vinculadas a nuestra temática de estudio. El Digesto tiene entre sus objetivos la derogación de todas aquellas leyes que por desuso o por resultar contradictorias fueron derogadas, lo cual ratifica la vigencia de las leyes que hemos analizado.

Son leyes que diseñan o conciben espacios institucionales a fin de canalizar la atención de la problemática, de donde surgen pautas a cumplir, respuestas a brindar, recursos a considerar, etc., en síntesis, que deben hacer y no hacer las instituciones que específicamente deben contribuir a que las mujeres vivan una vida sin violencia.

Este esquema se complementa con los instrumentos internacionales de derechos humanos incorporados a la Constitución Nacional, como lo son la Convención sobre la Eliminación de todas las Formas de Discriminación contra la Mujer (CEDAW) y la Convención Interamericana para Prevenir, Sancionar y Erradicar la Violencia contra la Mujer (Convención de Belém do Pará) y la Ley Nacional 26485 de "Protección integral para prevenir, sancionar y erradicar la violencia contra las mujeres en los ámbitos en que desarrollen sus relaciones interpersonales".

Las precitadas normas resultan ser de orden público y de aplicación en todo el territorio nacional, sin que medie necesidad explicita que las legislaturas provinciales adhieran a sus preceptos.

Las normas jurídicas que hemos identificado, por las responsabilidades y compromisos que imponen a los Estados, suelen ser fruto de una evidente
Entre lo dicho y lo hecho cuando se trata de mujeres

Mariano Eugenio Antón 
Dossier América Latina: género y política necesidad que lleva a poner en tensión el statu quo vigente hasta ese momento.

Sabido es que lograr una norma jurídica no resulta ser sencillo, son muchos los factores que se ponen en juego, técnicos, políticos, presupuestarios, culturales. Como bien lo afirma Guzmán (2001): "la legitimación e institucionalización de una nueva problemática no se da en el vacío, sino que tiene lugar en sociedades concretas, con distintos grados de diversidad cultural, de densidad organizativa y de sistema político; con culturas políticas y desarrollo institucional específicos, y con distinto nivel de desarrollo y de modernidad". Y con más precisión nos destaca y coincidimos en que "Las posibilidades de legitimar las desigualdades de género como problema público están condicionadas económica, política, legal e institucionalmente". La referencia precedente la efectuamos para no caer en un simple reduccionismo en relación con el pensamiento mágico de creer que la norma jurídica es un producto fácilmente realizable y ejecutable, tener la norma es algo, no es todo.

A su vez, no podemos ignorar que el Estado es un sujeto plural, cuyas acciones no resultan tan coordinadas y coherentes como se plantean en los instrumentos jurídicos; leyes y procedimientos, consignas y pautas, oportunidades y momentos son interpretados de diferentes modos por los funcionarios o agentes intervinientes (Segato, 2010, p. 105).

Lo dispuesto por la norma y su puesta en marcha nos dará una referencia sobre qué es lo que se intenta lograr, y resultará central a fin de evaluar si contribuyen a potenciar la igualdad o a perpetuar la desigualdad.

Muchos han creído y creen que la norma marca la agenda, que la norma jurídica constituye los derechos per se, pero la práctica indica que, si bien ello es un paso relevante, requiere de otras dimensiones que materialicen el enunciado. Segato nos ayuda a comprender que en reiteradas oportunidades:

Como todo discurso, la ley tiene el poder simbólico de dar forma a la realidad social (...). Las denuncias y aspiraciones que el discurso legal publica hacen posible que las personas identifiquen sus problemas y aspiraciones. Al espejarse en el discurso del derecho, pueden reconocerse y, reconociéndose, acceder a la comprensión precisa de sus insatisfacciones y sus pleitos. Desde la perspectiva de los minorizados, el discurso del derecho, siempre entendido como un eficaz sistema de nombres en permanente expansión, tiene el poder de agitación, el carácter de propaganda, aún apuntando en la dirección de lo que todavía no existe, que no es aún posible adquirir, en la vida social. (Segato, 2010, p. 105)

Tener la norma jurídica es mucho, su incumplimiento no debe desalentarnos, el esfuerzo es que si se ajusta a los estándares de derechos humanos logremos pronto que se constituya en la moralidad dominante.

Asimismo, "el diseño institucional deja constancia del resultado de la lucha por los recursos, los cargos, las facultades, las posibilidades y/o elementos que se encuentran en disputa" (Góngora, 2008, p. 145). La concreción institucio- 
nal, al igual que la concreción normativa se inscribe en el terreno de las luchas políticas.

Dicho lo precedente, nos parece adecuado destacar que el Comité para la Eliminación de la Discriminación contra la Mujer, que prevé la CEDAW, para el caso de la Argentina, en su informe del año 2016, ha manifestado en los acápites de nuestro interés que:

(...) el Comité observa que la Convención tiene prioridad sobre la legislación nacional en el Estado parte y puede ser aplicada directamente por los tribunales y las autoridades nacionales. Sin embargo, sigue preocupado por la ausencia de causas judiciales y procedimientos administrativos, en particular a nivel provincial y municipal, en casos en que las disposiciones de la Convención se invocaron o se aplicaron directamente. Le preocupa también que las disposiciones de la Convención, su Protocolo Facultativo y las recomendaciones generales del Comité no sean lo suficientemente conocidas en el Estado parte, sobre todo por las autoridades públicas. (CEDAW/C/ARG/CO/7, Acápite 8)

Ello indudablemente debería generar un primer síntoma de alarma. El Comité destaca la aprobación por el Estado Argentino de leyes esenciales para promover la igualdad sustantiva entre las mujeres y los hombres, pero expresa preocupación por: "La falta de aplicación efectiva del amplio marco legislativo para el adelanto de la mujer en el Estado parte, que ha dado lugar a una discriminación de facto contra la mujer" (CEDAW/C/ARG/CO/7, Acápite 10). El Comité, le recuerda observaciones anteriores donde instaba al Estado a que:

a) Determine las esferas en que la legislación provincial parece apartarse de las obligaciones que incumben al Estado parte en virtud de la Convención...", "b) Establezca mecanismos de rendición de cuentas para supervisar los efectos de la aplicación de la legislación destinada a promover la igualdad de género en todos los niveles de la jurisdicción, y destine suficientes recursos humanos, técnicos y presupuestarios a dicha aplicación; ... (CEDAW/C/ ARG/CO/7, Acápite 11)

Como podemos observar, las instancias internacionales de observación no solo indagan en cuanto al grado de implementación y aceptación de la normativa internacional que el Estado se ha comprometido a cumplir, sino también en cuanto al grado de avances en la implementación de la legislación interna, desarrollo de espacios institucionales acorde a los fines pretendidos y respuestas de la estructura administrativa y judicial.

En el ámbito de la OEA, bajo el mecanismo de seguimiento de implementación de la Convención Belén do Pará, el MESECVI ${ }^{2}$, en la producción

2 El MESECVI es una metodología de evaluación multilateral, fundamentada en un foro de intercambio y cooperación técnica entre los Estados Parte de la Convención y un Comité de
Entre lo dicho y lo hecho cuando se trata de mujeres

Mariano Eugenio Antón 
Dossier América Latina: género y política de su último informe ${ }^{3}$, en relación con la obligación de garantizar la accesibilidad a todos los medios, acciones y servicios sin discriminación alguna, se destaca que:

(...) el Comité observa que existe información y un avance relativo al componente formal de los derechos, es decir la ampliación de la cobertura..., gracias al reconocimiento formal en normas y leyes sobre violencia contra las mujeres y al establecimiento de medidas de protección, servicios especializados y sanciones. No obstante, la información disminuye cuando se intenta obtener información para conocer el grado de implementación de estas normas y su aplicación en la vida diaria de las mujeres y en especial de las mujeres que sufren múltiples factores de discriminación... (CEDAW/C/ ARG/CO/7, Acápite 266)

A partir de las consideraciones expuestas, es posible inferir que la Provincia de Misiones no puede resultar exenta a dichas observaciones.

A nivel Nacional, el Instituto Nacional contra la Discriminación, en su informe denominado "Plan Nacional contra la Discriminación" (INaDI, 2008, p. 99), da cuenta de que a pesar de la existencia de leyes nacionales y provinciales que abordan la problemática específica de violencia contra la mujer "los mecanismos institucionales para proteger a las víctimas siguen siendo insuficientes". El informe destaca que:

En este sentido, debe señalarse la falta de políticas públicas y programas integrales orientados a proveer recursos para la atención integral (psicológica, legal y social) de las víctimas de violencia doméstica. Son escasos los refugios para los momentos de crisis y no existen campañas generalizadas de prevención destinadas a modificar los patrones culturales que legitiman la violencia doméstica. Un aspecto fundamental que evidencia la negligencia (...) es el escasísimo presupuesto que destinan a prevenir y sancionar estos delitos, y asistir a las víctimas. (...) En las provincias donde existe legislación contra la violencia doméstica, no siempre las normas se cumplent.

A nivel provincial, no existe ningún mecanismo de seguimiento o espacio institucional que recopile la información de manera general relativa a las situaciones de violencia hacia las mujeres, más allá que desde lo normativo se indica que debería hacerlo la Subsecretaria de la Mujer. Esta falta de infor-

\footnotetext{
Expertas/os. El MESECVI analiza los avances en la implementación de la Convención, así como los desafíos persistentes en las respuestas estatales ante la violencia contra las mujeres.

3 Segundo Informe de Seguimiento a la Implementación de las Recomendaciones del Comité de Expertas del MESECVI, http://www.oas.org/es/mesecvi/docs/mesecvi-segundoinformeseguimiento-es.pdf (abril de 2015).

4 Cap. III Género. Hacia un Plan Nacional contra la Discriminación. B.O. de la Rep. Argentina. Año CXIII Número 30.747. Decreto Reg. 1086/2005.
} 
mación es uno de los grandes obstáculos para la formulación de las políticas públicas pertinentes.

Ya en lo provincial, en la Ley I No 106 que manda a crear el Departamento de la Mujer en las Comisarías de la Policía de la Provincia de Misiones, con la función principal de recepción de denuncias realizadas por mujeres, se ha constatado que este departamento aún no se ha creado, es decir no existe un área de atención específica para el abordaje de la violencia hacia las mujeres.

La ley precitada es del año 1996, nunca se crearon dichos espacios, sino que en 2004 se decidió establecer por medio del Decreto Provincial 628/045, la creación de Comisarías de la Mujer, con la pretensión de brindar atención específica y exclusiva a la problemática de violencia en el ámbito familiar ${ }^{6}$.

Por otro lado, la Ley Provincial II No 26 crea el Centro de Atención Integral de las Víctimas de Violencia, centro que al día de la fecha no se materializado en ningún organigrama institucional, ni tampoco las funciones, competencias, atribuciones y objetivos que determina la ley.

La ley bajo análisis trae consigo una propuesta que destacamos como valiosa y consiste en que el Centro informe mensualmente a la autoridad de aplicación sobre lo actuado y eleve semestralmente a la Cámara de Representantes una síntesis de casos atendidos y la evaluación de los resultados obtenidos en materia de recuperación de las víctimas. Lo lamentable es que este informe hasta la fecha nunca fue presentado bajo la forma, modalidad o fines que indica la norma.

Otra ley Provincial, la II N² $28^{7}$, crea el "Programa digamos no a la violencia”, que instituye la Brigada Móvil para la atención y asistencia a víctimas de delitos contra la integridad sexual y violencia familiar en situaciones de emergencia. De esta ley se deriva la implementación de la denominada Línea 137, receptora de denuncias sobre casos de violencia en casos exclusivos de emergencia. Por medio de esta línea telefónica se solicita la presencia inmediata de la Brigada Móvil, que sí funciona actualmente ${ }^{8}$ y es muy operativa.

Por otro lado, la Ley Provincial No II 30 del año 2016 propone la “Creación del Sistema Provincial de Casas-Refugio para Víctimas de Violencia Familiar”, a lo que debemos decir que esta Ley resulta ser idéntica a una anterior Ley

5 En los Vistos se reconoce "la necesidad de crear una dependencia especializada para la atención exclusiva de conflictos que puedan tener como sujeto a la mujer.”; en los Considerandos se reconoce "Que, existen una cantidad de delitos contra la mujer, en particular la violencia familiar y sexual, que por diferentes motivos - pudor, miedo, temor a la opinión de los demás o por ser el agresor sostén económico del grupo familiar- las víctimas no lo denuncian”.

6 Ámbito que cuestionamos dado que este tipo de comisarías específicas (de la mujer) funcionan solo en las grandes ciudades de la Provincia y no llegan a tener el alcance territorial necesario, no siempre resultan ser cercanas al domicilio de la víctima.

7 Sancionada el 04.10.2012.

8 “Habilitaron la línea 137 de asistencia a víctimas de violencia familiar”. Octubre 15, 2013. Disponible en http://misionesonline.net/2013/10/15/habilitaron-la-1-nea-137-de-asistencia-av-ctimas-de-violencia-familiar/

9 Sancionada el: 27-10-2016, Dec. Promulgación No: 1540.
Entre lo dicho y lo hecho cuando se trata de mujeres

Mariano Eugenio Antón 
Dossier América Latina: género y política
Provincial II N 17, del año 2004, denominada de "Protección y Atención Psicofísica al niño, niña, adolescente y adulto víctima de violencia familiar. Creación de Casa Refugio". La ley del año 2004 tenía por objeto garantizar la protección y atención psicofísica a víctimas de violencia familiar y a tal fin creaba las denominadas casas refugio que debían funcionar en la provincia de Misiones. Estas casas tenían como objetivo albergar transitoriamente a las víctimas de cualquier tipo de violencia. Ello resulta ser un curioso caso de actualización normativa que cambia de denominación, pero no de fines, objetivos o funciones, en palabras sencillas la ley II No 30 de 2016 vuelve a proponer crear lo que ya debía haber sido creado o materializado por la ley del año 2004.

En relación con estén último punto, encontramos en declaraciones del Ministro de Desarrollo dos referencias a la materialización de las casas refugio, una en agosto de 2016 donde se informa que en cuanto a las casas refugio se acaba de cerrar trato con un lugar adaptado a la problemática diseñado por especialistas, y que contará con profesionales que trabajan en el tema con mucha experiencia y profesionalidad. Luego, en diciembre de 2017, en las jornadas "Políticas de Género: Charlemos entre nosotras", que se desarrollaron en la Cámara de Representantes de Misiones, el ministro informó de la inauguración de dos casas refugio para víctimas de violencia de género, "para la contención profesionalizada"; y un refugio para víctimas de la trata de personas. Las declaraciones expuestas resultan ser las primeras referencias desde el reconocimiento legal de la necesidad de creación de las casas refugio en el año 2004.

Finalmente, la Ley Provincial XIV No $6^{10}$, denominada de Violencia Familiar, resulta ser la ley específica para el abordaje de la violencia familiar, y concomitantemente la que se utilizaba para abordar la problemática de violencia hacia las mujeres. El limitante que acarreaba esta ley es que solo posee alcance para la violencia ejercida en el ámbito familiar, cuestión que hoy se encuentra superada por la adhesión ${ }^{11}$ de la Provincia a la ley Nacional 26.485 que protege a la mujer en cualquier ámbito en que desarrolle sus relaciones interpersonales. Con anterioridad a la adhesión a la Ley Nacional se presentaban muchísimas dificultades por parte de los espacios de acceso a la justicia (comisarías y juzgados de paz) para tramitar los casos en que las mujeres sufrían violencia por fuera del ámbito familiar.

Esta ley concibe una serie de acciones y medidas que el Estado Provincial debería desarrollar. De este listado destacamos que no se han implementado en los centros de salud dependientes de la Provincia equipos multidisciplinarios de atención a víctimas y sus familias; tampoco se ha destinado en

\footnotetext{
10 Sancionada 29 de noviembre de 2007.

11 Aunque la Ley Nacional resulta ser de orden público y de aplicación en todo el territorio Nacional, la misma no resultaba ser utilizada por los operadores del sistema por entenderse que la Provincia no se encontraba adherida, lo cual dejaba muchas situaciones por fuera de la posibilidad de tutela.
} 
las Comisarías personal especializado en la materia junto a un lugar privado para la atención de víctimas (Antón, 2017). Tampoco existe o se ha podido detectar en la Provincia programa alguno dirigido a los varones golpeadores, pese al reconocimiento de su necesidad en varias leyes provincialesLa ley, además, prevé la creación de un "Cuerpo de Patrocinantes Letrados Gratuito", destinado a brindar asesoramiento y patrocinio a las víctimas de violencia familiar, junto a la consigna de crear un "Registro Provincial de Actuaciones de Violencia Familiar", que debería depender de la Dirección de Violencia Familiar y de Género, al cual deben remitir jueces y funcionarios públicos actuantes los datos e identificación de la causa. En relación con estos espacios institucionales debemos con pena decir que a la fecha no se han instrumentado ninguno de ellos.

Las tensiones o carencias detectadas nos permiten afirmar que existe una distancia entre las políticas públicas que la ley ha previsto y lo realmente desarrollado, como también distancia entre los diseños institucionales propuestos en la norma vigente y la organicidad institucional lograda, lo que genera una sensación de fracaso del sistema.

\section{Responsabilidades}

Entonces ¿cuáles son las consecuencias de un obrar omiso o deficiente por parte del Estado? Para ello es pertinente compartir el análisis que efectúa en varios trabajos de investigación la Organización Panamericana de la Salud (OPS), al indagar sobre la posibilidad de que sea el propio Estado, al prestar un servicio deficiente, el que contribuya a dificultar que una mujer pueda salir de la situación de violencia a la que se encuentra sometida.

Así en la publicación La Ruta Crítica que Siguen las Mujeres Afectadas por la Violencia Intrafamiliar en América Latina (Sagot, 2000, p.7), se da cuenta sobre cuáles son los diversos caminos que emprenden las mujeres para intentar salir de la situación de violencia en la que se encuentran. Al desarrollar el esquema teórico se enuncian los factores que impulsan o inhiben a las mujeres a buscar ayuda, las dificultades encontradas, sus percepciones sobre las respuestas institucionales y las representaciones sobre la violencia hacia la mujer que existen en el personal de las instituciones obligadas a actuar. De la multiplicidad de aristas respecto a la "Ruta Crítica" nos hemos centrado en los aspectos institucionales de respuestas.

Allí la OPS afirma que:

(...) la percepción de las mujeres de que no hay servicios o respuestas sociales para apoyarlas a resolver su problema, o que los servicios existentes son poco eficientes, inadecuados y hasta dañinos [conduce indefectiblemente a que] muchas mujeres afectadas se vean imposibilitadas o se nieguen a denunciar la violencia de la que son objeto [entre otras cosas porque] las
Entre lo dicho y lo hecho cuando se trata de mujeres

Mariano Eugenio Antón 
Dossier América Latina: género y política instituciones prestatarias de servicios, en general no cuentan con sistemas de detección y registro apropiados, lo que oculta aún más este serio y extendido problema social [sumado a que] existen también serios problemas en relación con la comprensión de las dinámicas de las relaciones violentas y de las experiencias de las personas afectadas. (Sagot, 2000, pp. 13-14)

Las apreciaciones de las propias mujeres sobre cómo se sienten atendidas por las instituciones públicas, y de las consecuencias que ello podría acarrear, amerita pensar en que las consecuencias dañosas que se deriven de ese obrar deficiente, requerirá que se detecte un responsable, máxime cuando las normas vigentes así lo indican, y el Estado se ha comprometido a lograr "por todos los medios apropiados y sin dilaciones, una política encaminada a eliminar la discriminación contra la mujer" (Art. 2 de la CEDAW).

Observar las respuestas institucionales implica saber que existen factores que impulsan y otros que inhiben a las mujeres a permanecer o no en una relación violenta. La OPS destaca dentro de los inhibidores externos las actitudes negativas de los prestatarios y las inadecuadas respuestas institucionales, así como la limitada cobertura de las organizaciones gubernamentales y los contextos sociales que naturalizan las historias de violencia.

Las respuestas institucionales que se brindan, el acceso, disponibilidad y calidad de los servicios están determinados tanto por factores estructurales y normativos, como por las representaciones sociales y comportamientos de los que deben brindar atención. Dichas respuestas operan sobre la subjetividad de las mujeres para fortalecerlas o debilitarlas en su decisión de iniciar o continuar la búsqueda de soluciones.

Remarca la OPS que, al iniciar el camino de intentar salir de la violencia, en muchas ocasiones los riesgos aumentan para las mujeres con "las respuestas negativas o revictimizantes encontradas en las instituciones a las que acudieron" y que "les enseñaron que hablar y pedir apoyo no siempre les ayuda a enfrentar los problemas y que, por el contrario, les acarrea grandes riesgos".

Se sabe que la decisión más difícil es la de formular una denuncia o acudir a cualquiera de las instancias del sistema judicial o policial, y que previo a ello las mujeres han acudido a otras instituciones con la esperanza de poder cambiar la situación sin tener que llegar a este punto. Esta, sin embargo, es una decisión de suma importancia, pues sugiere que las mujeres que la toman han entendido que su problema no pertenece más al ámbito de lo privado. La falta de adecuadas respuestas institucionales genera un impacto en la mujer que la vuelve al punto cero, que sería el retorno al círculo de la violencia en la cual se encontraba inmersa, pero en este caso agravado por el descreimiento y resignación ante la falta de respuestas institucionales.

Desde lo normativo, la Ley provincial XIV No 6 enuncia en su artículo $2^{\circ}$ que:

En caso de que (los servicios asistenciales sociales, educativos o sanitarios, de seguridad públicos o privados, y todo otro funcionario público en 
razón de su labor)... incumplan con la obligación establecida, el Juez interviniente debe citarlos de oficio a la causa y remitir los antecedentes al fuero penal. De igual manera procederá respecto del tercero o superior jerárquico que por cualquier medio interfiriera, obstaculizara o impidiera la denuncia. El texto asigna responsables por no hacer lo que se espera que hagan.

Por su parte la ley Nacional № 26485, en su Artículo $4^{\circ}$, al definir a la violencia contra las mujeres, destaca que de las posibles modalidades de violencias que puede sufrir una mujer "quedan comprendidas las perpetradas desde el Estado o por sus agentes". Por lo que queda prescripto que el Estado puede dañar por acción o por omisión, que es lo que en definitiva entendemos que hace cuando se compromete a algo que luego no concreta.

En relación con destacado que hemos efectuado, le sumamos la consideración de la Convención Americana que también incluye a la que "....sea perpetrada o tolerada por el Estado o sus agentes, donde quiera que ocurra." $\left(\right.$ art. $\left.2^{\circ}\right)$. No hacer cuando se debe es una actuar omiso cuestionado por la normatividad vigente.

Las referencias normativas nos permiten afirmar que la omisión o la deficiencia en la prestación del servicio de tutela se encuentran cuestionados, y abre la posibilidad de que al darse determinada relación causal se pueda imputar responsabilidades personales e institucionales.

Con mayor precisión, la Ley Nacional 26485, al referirse a las modalidades de violencia indica en el art. 6 inc. b) que:

La violencia institucional contra las mujeres: es aquella realizada por las/los funcionarias/os, profesionales, personal y agentes pertenecientes a cualquier órgano, ente o institución pública, que tenga como fin retardar, obstaculizar o impedir que las mujeres tengan acceso a las políticas públicas y ejerzan los derechos previstos en esta ley.

Si se legisla, se prevé la política pública, se prevé un espacio institucional, se determinan obligaciones específicas, pero no se concreta lo que el legislador concibió como adecuado y necesario para contribuir en la erradicación de la violencia hacia la mujer, entonces nos es indudable que a alguien se le tenga que imputar alguna responsabilidad.

En esta línea en Antropología, violencia y justicia (Rifiotis, 2011), se destaca que el Estado de ordinario ejerce una violencia no autorizada y que dicha violencia incluye el no hacer cuando se debería. Aquí también se sostiene que el crecimiento institucional y legal resulta ser una interesante pauta de cómo los Estados van adoptando las reglas del contexto de universalización de los derechos humanos como una inequívoca ampliación de los derechos humanos, pero es aquí la pregunta que motivó el trabajo y que podría ser también la nuestra ¿Significan estos avances legislativos una verdadera disminución en la violación de los derechos?
Entre lo dicho y lo hecho cuando se trata de mujeres

Mariano Eugenio Antón 
Dossier América Latina: género y política
Conforme lo expuesto, la normatividad es un inicio, resulta relevante que exista un esquema que institucionalice, que nombre, que reconozca problemáticas, ahora bien:

(...) lo jurídico puede ser al mismo tiempo una solución y un problema... Esto nos coloca en una situación de alerta frente a los cambios normativos más actuales, en tanto entendemos que ni las nuevas leyes en relación con la violencia son un fin en sí mismo, ni tampoco los objetivos sociales proyectados sobre esas leyes se realizan automáticamente. Por el contrario, su efectividad depende de un monitoreo continuo. (Rifiotis, 2011, p. 7)

En el ámbito internacional, la pauta interpretativa de cómo no debe actuar el Estado al tomar conocimiento de un caso de violencia contra una mujer, la observamos en el caso "Maria da Penha vs. Brasil"12, donde la Comisión Interamericana de Derechos Humanos entendió que el Estado Brasileño había violado en perjuicio de la señora Maria da Penha los derechos a las garantías judiciales y a la protección judicial garantizados en la Convención Americana, en la Declaración y en Belém do Pará. Concluyendo que dicha violación de derechos se dio como parte de un patrón discriminatorio respecto a la tolerancia de la violencia doméstica contra las mujeres en Brasil. La CIDDHH responsabilizó al Estado por omisión, negligencia y tolerancia a la violencia doméstica contra las mujeres brasileñas. Se afirmó en dicha oportunidad que

...la segunda obligación de los Estados Partes es la de "garantizar" el libre $y$ pleno ejercicio de los derechos reconocidos en la Convención a toda persona sujeta a su jurisdicción. Esta obligación implica el deber de los Estados Partes de organizar todo el aparato gubernamental y, en general, todas las estructuras a través de las cuales se manifiesta el ejercicio del poder público, de manera tal que sean capaces de asegurar jurídicamente el libre y pleno ejercicio de los derechos humanos. Como consecuencia de esta obligación los Estados deben prevenir, investigar y sancionar toda violación de los derechos reconocidos por la Convención y procurar, además, el restablecimiento, si es posible, del derecho conculcado y, en su caso, la reparación de los daños producidos por la violación de los derechos humanos. (párrafo 43)

Citamos esta opinión de la Corte Interamericana porque entendemos que se torna compleja la situación de los Estados, si por un lado en su esquema normativo enuncian lo que entienden necesario desarrollar o implementar para contribuir a disminuir la violencia hacia la mujer y luego no lo cumplen, no lo materializan.

12 Comisión Interamericana de Derechos Humanos, Informe $\mathrm{N}^{\circ}$ 54/01, CASO 12.051. $16 / 04 / 01$. 
Por otro lado la Corte Interamericana a través del paradigmático caso "González y otras ("Campo algodonero") vs. México"13, sostuvo que los Estados deben adoptar medidas integrales para cumplir con la debida diligencia en casos de violencia contra las mujeres. En particular, deben contar con un adecuado marco jurídico de protección, con una aplicación efectiva del mismo y con políticas de prevención y prácticas que permitan actuar de una manera eficaz ante las denuncias. La estrategia de prevención debe ser integral, es decir, debe prevenir los factores de riesgo y a la vez fortalecer las instituciones para que puedan proporcionar una respuesta efectiva a los casos de violencia contra la mujer.

Todo incumplimiento al compromiso asumido por el Estado, que podría ser una omisión, en este caso la de no desarrollar los espacios institucionales pertinentes, debería entrañar la responsabilidad de éste. Claro está que debería surgir la imputación luego de determinada la relación causal, entre omisión y daño.

La relación causal para imputar responsabilidad se daría si, por ejemplo, la mujer acude a una dependencia pública, ésta no brinda la respuesta comprometida acorde a la magnitud del problema, ésta mujer regresa a su casa frustrada y se vuelve a encontrar con el violento, que sabiéndose impune arremete sobre las debilitadas fuerzas físicas y psicológicas de la mujer, si le produce su muerte o casi, entendemos que no será difícil relacionar el triste desenlace con la respuesta deficitaria del Estado.

La normatividad vigente obliga a los Estados a proteger los derechos de las mujeres y su no hacer se constituye en una violación a los derechos humanos. El Estado Argentino ha asumido el compromiso de velar por que las autoridades, sus funcionarios, personal y agentes e instituciones se comporten de conformidad con la obligación precitada; a más que deberá adoptar las medidas administrativas apropiadas que sean del caso; y desarrollará medidas para modificar prácticas jurídicas o consuetudinarias que respalden la persistencia o la tolerancia de la violencia contra la mujer; estableciendo los mecanismos judiciales y administrativos necesarios para asegurar que la mujer objeto de violencia tenga acceso efectivo a resarcimiento, reparación del daño u otros medios de compensación justos y eficaces. Esas dimensiones no parecieran estar cumpliéndose en la provincia de Misiones.

La Cámara Nacional en lo Contencioso Administrativo Federal ${ }^{14}$, sostuvo que cabe detenerse aquí en los deberes de prevenir, sancionar y erradicar la violencia contra la mujer... En particular, cabe poner de resalto que los Estados partes deberán velar por que las autoridades, sus funcionarios, personal y agentes e instituciones se comporten de conformidad con esta obligación; es

${ }^{13}$ cfr. Corte IDH, caso González y otras “Campo Algodonero” vs. México. Excepción Preliminar, Fondo, Reparaciones y Costas. Sentencia de 16 de noviembre de 2009. Serie C No. 205.

14 A., R.H. y Otra c/ E.N. M Seguridad - P.F.A. y Otros s/ daños y perjuicios, Expte. nro. $50.029 / 2011$. Sentencia de julio de 2017, Sala II.
Entre lo dicho y lo hecho cuando se trata de mujeres

Mariano Eugenio Antón 
Dossier América Latina: género y política decir que los órganos de los poderes públicos deben comportarse de tal modo que se ajusten a los compromisos que asumen sus países.

En el caso precitado se estableció la relación del actuar deficiente de los agentes policiales, con la consecuencia fatídica del asesinato de una mujer a manos de su marido, se atribuyó responsabilidad al Estado citando a la Ley $\mathrm{n}^{\circ} 26485$ y la Convención de Belén do Pará. Afirmándose que a raíz de estas normas, sobre el Estado pesa el deber de garantizar la asistencia integral y oportuna a las mujeres que padecen violencias, con miras a que éstas accedan de modo gratuito, rápido y eficaz a los servicios creados al efecto. A lo que se agregó que las previsiones normativas vigentes son suficientes para deducir que no se ajusta a derecho un proceder que no se oriente, en lo que al caso interesa, a la prevención, investigación, y sanción de dicha violencia, o que implique tolerancia a patrones culturales o de conducta que importen la perpetuación de dicha violencia.

Entonces de todo lo expuesto, para hacer responsable al Estado por omisión o deficiencia en la prestación, se deberán registrar las siguientes circunstancias: 1) que exista una situación de riesgo real o inmediato que amenace derechos y que surja de la acción o las prácticas de particulares; esto es, se requiere que el riesgo no sea meramente hipotético o eventual y, además, que no sea remoto, sino que tenga posibilidad cierta de materializarse de inmediato; 2) que la situación de riesgo amenace a una mujer, es decir, que exista un riesgo particularizado; 3) que el Estado conozca el riesgo o hubiera debido razonablemente conocerlo o preverlo; 4) finalmente que el Estado pueda razonablemente prevenir o evitar la materialización del riesgo (esta misma enumeración extraída del precedente "Campo Algodonero").

Por ello, de darse las estipulaciones precedentes, entendemos que resulta ineludible comprender que los Estados, por medio de sus distintos espacios institucionales, tienen una clara obligación de cumplir los compromisos asumidos. Ello porque cuando existe un compromiso viene ínsita la obligación, las leyes son claras y las responsabilidades que ellas determinan también.

\section{Conclusiones}

Evidentemente las acciones del Estado, como sujeto plural, no resultan tan coordinadas y coherentes como se plantean en los instrumentos jurídicos; que a su vez son interpretados de diferentes modos por los funcionarios intervinientes, más en estos temas donde la distancia entre las dimensiones "etic" y "emic" son la regla; es decir entre el "deber ser" como contrato social y el efectivo "hacer" como estatus social ${ }^{15}$.

${ }_{15}$ M. Antón y I. Schiavoni, Negar un derecho y trastocar la vida de una niña. Trabajo presentado en la X Reunión de Antropología del Mercosur. Córdoba 10/6/13. GT61. 
Esas distancias poco entran en análisis, inclusive actores de la sociedad civil muchas veces piden al legislador más normatividad, y en eso radica su lucha, sin atender que aún si quiera se ha cumplido con lo ya consagrado.

En las violencias hacia las mujeres, como problema cultural de todo el tejido social, la legislación vigente incluida la fundamentación que da razón a la misma no resulta fácil de internalizar, por ello el desarrollo de la política pública esta distante de lo enunciado normativamente.

El Estado se compromete a hacer y no hace. El riesgo es que el comportamiento que desarrollan las instituciones estatales, al ser requeridas, puede impulsar o inhibir a una mujer para que salga de una vida de violencia. La distancia entre normatividad y política pública, el actuar omiso, deficiente o negligente del Estado debe y tiene consecuencias.

La importancia que revisten las leyes como expresión de los derechos y los efectos de su divulgación son la garantía para que las mujeres no queden libradas a la interpretación que algunos hagan sobre lo que se debe o no hacer.

Los obstáculos institucionales, los desafíos que se deben enfrentar para hacer valer la ley, no son exclusivamente de tipo económico o material sino y fundamentalmente de orden político cultural.

Y ello seguirá sucediendo en tanto y en cuanto ello no sea puesto en evidencia y se logre establecer la relación causal entre la omisión estatal y el daño producido. Mientras tanto se seguirá haciendo como que.

\section{Referencias bibliográficas}

Antón, M. y Schiavoni, L. (2013). Negar un derecho y trastocar la vida de una niña. Trabajo presentado en la X Reunión de Antropología del Mercosur. Córdoba 10/06/13. GT61.

Antón, M. (2917). Golpeando Puertas. Colección Ciencias Jurídicas, 1º Edic. Posadas, Misiones: Editorial UGD.

Bardales, O. y otros (2012). Feminicidio bajo la lupa. MIMP. Recuperado 30.04 .2019 de https://www.mimp.gob.pe/files/programas_nacionales/pncvfs/feminicidio_bajo_la_lupa.pdf

CEDAW/C/ARG/CO/7 (2016). Reseña: Evaluación del Comité para la Eliminación de la Discriminación contra la Mujer. País: Argentina.

Corte IDH (2009). Caso González y otras “Campo Algodonero” vs. México. Sentencia de 16/11/09. Serie C No 205.

Comisión IDH (2001). Informe $\mathrm{N}^{\circ}$ 54/01, CASO 12.051. 16/04/01.

Garcia Villegas, M. (2011). Ineficacia del derecho y cultura del incumplimiento de reglas en América Latina. En C. Rodriguez Garabito (Coord.), El derecho en América Latina. $1^{\circ}$ Edic. Buenos Aires: Siglo XXI Editores.

Góngora, M. F. (2008). El diseño institucional. En M. Gerlero, Los silencios del derecho, cap. IV. Buenos Aires: Edit. David Grimberg Libros Jurídicos.

Gonzalez, U. (2009). Violencia domestica: estrategias legales y experiencias judiciales. En C. Santagati, Colección de Derechos Humanos, $2^{\circ}$ Edic. Buenos Aires: Ediciones Jurídicas.
Entre lo dicho y lo hecho cuando se trata de mujeres

Mariano Eugenio Antón 
Dossier América Latina: género y política
Guzmán, V. (2001). La institucionalidad de género en el Estado: nuevas perspectivas de análisis. Serie no. 32 Mujer y Desarrollo. Santiago de Chile: CEPAL.

Moreira, M. y otra (2016). El abordaje de la violencia contra la mujer en las comisarías de la ciudad de Posadas. En Genero, Violencia y Derechos Humanos. Posadas: Ediciones CEDEA.

Rifiotis, T. y otra (2011). Antropología, violencia y justicia: repensando matrices de la sociabilidad contemporánea en el campo del género y la familia. $1^{\circ}$ Edic. Buenos Aires: Edit. Antropofagia.

Sagot, M. (2000). La ruta crítica de las mujeres afectadas por la violencia intrafamiliar en América Latina (Estudios de caso de diez países), O.P.S., Edic. Zeta Servicios Gráficos. Recuperado 30.04.2019 de http://ns.bvs.hn/docum/ops/libros/rutacritica.pdf

Schiavoni, L. (2012). Ejercicios para conceptualizar la violencia. Ponencia Seminario Multidisciplinario Sobre Violencia de Género organizado por CEDEAD, Posadas.

Segato, R. (2010). La argamasa jerárquica: violencia moral, reproducción del mundo y la eficacia simbólica del derecho. En Las estructuras elementales de la violencia. Ensayos sobre género entre la antropología, el psicoanálisis y los derechos humanos. Buenos Aires: Prometeo-UNQ.

Villalpando, W. (Coord.). (2008). Hacia un plan nacional contra la discriminación: la discriminación en Argentina. $1^{\text {a }}$ ed. Buenos Aires: INADI. 